Article

\title{
Wetting Resistance of Commercial Membrane Distillation Membranes in Waste Streams Containing Surfactants and Oil
}

\author{
Lies Eykens ${ }^{1,2, *}$, Kristien De Sitter ${ }^{1}$, Chris Dotremont ${ }^{1}$, Wim De Schepper ${ }^{1}$, Luc Pinoy ${ }^{3}$ \\ and Bart Van Der Bruggen ${ }^{2,4}$ \\ 1 VITO_Flemish Institute for Technological Research, Boeretang 200, 2400 Mol, Belgium; \\ kristien.desitter@vito.be (K.D.S.); chris.dotremont@vito.be (C.D.); wim.deschepper@vito.be (W.D.S.) \\ 2 Department of Chemical Engineering, Katholieke Universiteit Leuven, Celestijnenlaan 200F, \\ B-3001 Leuven, Belgium; bart.vanderbruggen@kuleuven.be \\ 3 Department of Chemical Engineering, Cluster Sustainable Chemical Process Technology, KU Leuven, \\ Gebroeders Desmetstraat 1, B-9000 Ghent, Belgium; luc.pinoy@kuleuven.be \\ 4 Faculty of Engineering and the Built Environment, Tshwane University of Technology, Private Bag X680, \\ Pretoria 0001, South Africa \\ * Correspondence: lies.eykens@vito.be; Tel.: +32-14-33-5663
}

Academic Editor: Enrico Drioli

Received: 13 December 2016; Accepted: 20 January 2017; Published: 25 January 2017

\begin{abstract}
Water management is becoming increasingly challenging and several technologies, including membrane distillation (MD) are emerging. This technology is less affected by salinity compared to reverse osmosis and is able to treat brines up to saturation. The focus of MD research recently shifted from seawater desalination to industrial applications out of the scope of reverse osmosis. In many of these applications, surfactants or oil traces are present in the feed stream, lowering the surface tension and increasing the risk for membrane wetting. In this study, the technological boundaries of MD in the presence of surfactants are investigated using surface tension, contact angle and liquid entry pressure measurements together with lab-scale MD experiments to predict the wetting resistance of different membranes. Synthetic $\mathrm{NaCl}$ solutions mixed with sodium dodecyl sulfate (SDS) were used as feed solution. The limiting surfactant concentration was found to be dependent on the surface chemistry of the membrane, and increased with increasing hydrophobicity and oleophobicity. Additionally, a hexadecane/SDS emulsion was prepared with a composition simulating produced water, a waste stream in the oil and gas sector. When hexadecane is present in the emulsion, oleophobic membranes are able to resist wetting, whereas polytetrafluoretheen (PTFE) is gradually wetted by the feed liquid.
\end{abstract}

Keywords: membrane distillation; wetting; sodium dodecyl sulfate; hexadecane

\section{Introduction}

Membrane distillation (MD) is a thermally-driven membrane separation process, mostly applied to separate salts from an aqueous solution. The process uses a hydrophobic membrane to retain the liquid phase, while vapor is transported through the microporous structure. In direct contact membrane distillation, the membrane can be considered a contactor between the process liquids and the vapor phase, enabling $100 \%$ retention of dissolved components. Critical for the process is that the membrane pores are not wetted by the process liquids. As with any thermal separation process, MD is considered less energy efficient than reverse osmosis [1]. However, unlike reverse osmosis, MD can be applied using low-grade waste heat, solar or geothermal energy, considerably reducing the energy costs [2]. Moreover, the process flux and salt retention are less affected by salinity of the 
feed and therefore the process is able to operate properly up to saturation [3,4]. Recently, membrane distillation has been applied more and more for challenging water streams with a much higher load of contaminants compared to seawater desalination. Examples include reverse osmosis (RO) brines [5-7], industrial waste water $[8,9]$ and produced water $[10,11]$. In many of the applications, the contaminants include a combination of less soluble salts, organic foulants or components lowering the surface tension of the process fluids. The occurrence of scaling and fouling of these contaminants can decrease the performance of the membrane [6,12-19]. Another less investigated phenomenon is membrane wetting, where despite the hydrophobicity and controlled pore size, liquid is able to penetrate into the membrane. The liquid entry pressure (LEP) indicates the minimum pressure difference over the membrane at which membrane wetting will occur and is given by [20]:

$$
L E P=-\frac{2 \gamma_{\mathrm{L}} \cos \theta}{r_{\max }}
$$

where $\gamma_{\mathrm{L}}$ is the surface tension of the liquid, $\theta$ the contact angle of the liquid with the surface and $r_{\max }$ the maximum pore radius.

Multiple origins of membrane wetting are known. Different MD studies show that the reduced hydrophobicity $(\theta)$ due to membrane fouling is a possible cause of membrane wetting [21,22]. Furthermore, defects present in the membrane influence $r_{\max }$ and therefore strongly affect the liquid entry pressure $[23,24]$. The main focus of this article is the presence of organics lowering the surface tension $\left(\gamma_{\mathrm{L}}\right)$ of the feed stream, which can cause wetting as well $[20,25,26]$. The effect of membrane wetting for a series of alcohols, organic acids and solvents was already investigated [20,25]. Different approaches were used to quantify the wetting resistance of a membrane towards the presence of an organic component:

The determination of the concentration and surface tension $\left(\gamma_{\mathrm{pd}}\right)$ at which a droplet wets the membrane (penetrating drop method) for each organic component.

Determination of the theoretical maximum allowable surface tension in the process $\left(\gamma_{\mathrm{pc}}\right)$ using [25]:

$$
\gamma_{\mathrm{pc}}=\gamma_{\mathrm{pd}}+\frac{\Delta \mathrm{P} \cdot r_{\max }}{2 B}
$$

Where $\Delta \mathrm{P}$ is the pressure drop over the membrane, $r_{\max }$ the maximum membrane pore size and $\mathrm{B}$ a geometric factor between 0 and 1 , where 1 indicates a perfectly cylindrical pore.

Measurement of the liquid entry pressure occurs as a function of the liquid composition.

Whereas the effect of alcohols, organic acids and solvent on the wetting behavior is described in literature $[20,25]$, the effect of surfactants and oil traces on the membrane distillation performance has been less studied. Lin et al. [26] observed membrane wetting of a $0.45 \mu \mathrm{m}$ polytetrafluoretheen (PTFE) membrane at a sodium dodecyl sulfate (SDS) concentration of $28 \mathrm{mg} / \mathrm{L}$, while a chemically-modified omniphobic membrane was able to resist wetting up to $115 \mathrm{mg} / \mathrm{L}$ SDS. Wang et al. showed that a $1000 \mathrm{ppm}$ crude oil mixture immediately wets a $0.45 \mu \mathrm{m}$ polyvinylidene fluoride (PVDF) membrane [27], while $100 \mathrm{ppm}$ mineral oil is shown to substantially wet the membrane after $21 \mathrm{~h} \mathrm{[28].}$

This study aims to improve the understanding of membrane wetting in the presence of surfactants and oil. A commonly used surfactant, sodium dodecyl sulfate, was used to investigate the effect on surface tension, contact angle and membrane wetting in membrane distillation. The validity of a simple methodology correlating the surface tension, contact angle and liquid entry pressure to membrane wetting in membrane distillation was investigated for different concentrations of sodium dodecyl sulfate. Moreover, different membranes were used to investigate the influence of surface chemistry. Finally, a standard oil-in-water emulsion was prepared and tested with MD. The composition simulates the composition of produced water, which is a common waste stream in the oil and gas production [29]. 


\section{Materials and Methods}

Three different microporous membranes were used in this study: PTFE (Tetratex, Donaldson Company Inc., Belguim, Leuven), polyethylene (PE) (Solupor ${ }^{\circledR}$, Lydall Inc., Rochester, NH, USA) and oleophobic polyethersulfone (PES) (Supor ${ }^{\circledR}$, Pall Corporation, New York, NY, USA). Sodium chloride (technical grade), Sodium dodecyl sulfate (SDS; $98 \%$ ) and hexadecane $(99 \%)$ and were purchased from Sigma Aldrich (Saint Louis, MO, USA).

Solutions with a concentration of $35 \mathrm{~g} / \mathrm{L}$ sodium chloride and different concentrations of sodium dodecyl sulfate ranging from 10 to $150 \mathrm{mg} / \mathrm{L}$ were prepared under continuous stirring for $1 \mathrm{~h}$. The oil-in-water emulsion was prepared with $2400 \mathrm{mg} / \mathrm{L}$ hexadecane, $240 \mathrm{mg} / \mathrm{L}$ sodium dodecyl sulfate and $10 \mathrm{~g} / \mathrm{L} \mathrm{NaCl}$. The components were mixed and ultrasound was applied for $30 \mathrm{~min}$ to stabilize the suspension. For the oil-in-water emulsion, the size of the oil droplets was measured by a particle size analyzer (Nanosight NS500, Malvern Instruments Ltd., Malvern, UK) and was found in the range of $0.1-0.5 \mu \mathrm{m}$ with an average particle diameter of $0.3 \mu \mathrm{m}$ [29].

The surface tension of the liquids was measured using a Force Tensiometer K6 from Kruss GmbH (Hamburg, Germany). The contact angle of the membranes was measured with an OCA 15EC Contact Angle System of Dataphysics (Filderstadt, Germany) using the static sessile drop method. The critical surface tension of wetting was determined for the PES membrane by measuring the contact angles using a series of alkanes (from hexadecane to hexane). The surface tension of the liquid that first shows a contact angle below $90^{\circ}$, i.e., the liquid that wets the membrane is assumed as the critical surface tension. For PTFE and PE, literature values are used. The liquid entry pressure was determined as described by Khayet et al. [30]. The hydrostatic pressure was increased slowly by 0.1 bar each $30 \mathrm{~s}$, until a flow was detected. The porosity was measured using helium pycnometry as described in [31]. The thickness was obtained by imaging the membrane cross-section using a cold field emission scanning electron microscope (SEM) type JSM6340F (JEOL, Tokyo, Japan) as described in [31]. The average and maximum pore size were measured using a Porolux ${ }^{\circledR} 1000$, with Porefil as wetting liquid and the shape factor assumed to be 1 [31].

The direct contact membrane distillation (DCMD) experiments were carried out using the experimental setup described in [32]. The process scheme of the setup is visualized in Figure 1. The module had a membrane area of $0.0108 \mathrm{~m}^{2}$ and $2 \mathrm{~mm}$ thick polypropylene (PP) spacers were used. The feed and permeate temperatures were kept constant at 60 and $45^{\circ} \mathrm{C}$, respectively, for each experiment. The flow velocity was $0.13 \mathrm{~m} / \mathrm{s}$ at feed and permeate side. The first MD test included a stepwise increase of the concentration of SDS up to $150 \mathrm{mg} / \mathrm{L}$. These experiments were run for $2 \mathrm{~h}$ at each concentration. Additionally, longer tests were performed using $150 \mathrm{mg} / \mathrm{L}$ SDS, where the flux was measured over three days.

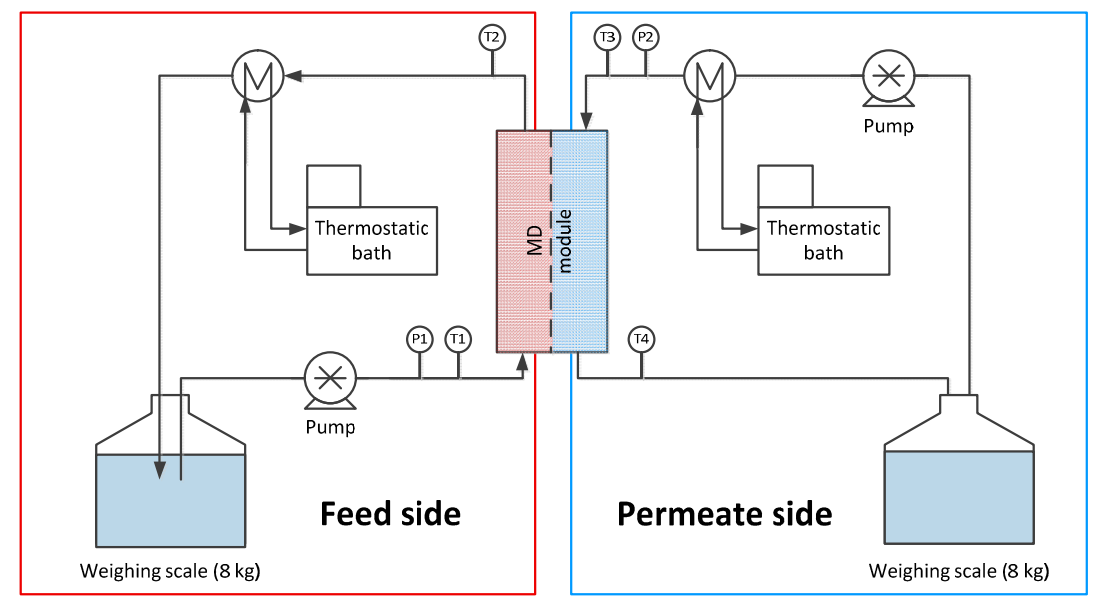

Figure 1. Process scheme of the direct contact membrane distillation (DCMD)-lab scale setup. T indicates a temperature sensor, P refers to pressure sensors. 


\section{Results}

\subsection{Membrane Characterization}

The thickness $(\delta)$, porosity $(\varepsilon)$ andmean pore size $\left(d_{\text {mean }}\right)$ of the membranes used in this study is given in Table 1. These properties mainly determine the absolute flux [33]. The maximum pore size $\left(d_{\text {max }}\right)$ and water contact angle $\left(\theta_{\text {water }}\right)$ are mostly important for the wetting resistance, which is sufficiently high for pure water. The water contact angle for the PTFE membrane is the highest $\left(138^{\circ}\right)$, followed by the PES membrane $\left(132^{\circ}\right)$ and the PE membrane $\left(120^{\circ}\right)$. The hexadecane contact angle $\left(\theta_{\text {hexadecane }}\right)$ is used to test the oleophobicity of the membranes. As expected, PTFE and PE do not show any resistance to wetting of hexadecane, whereas the oleophobic PES membrane shows a contact angle of $92^{\circ}$ with hexadecane.

Table 1. Properties of the membranes used in this study.

\begin{tabular}{cccccccc}
\hline Membrane & $\delta(\mu \mathrm{m})$ & $\varepsilon(\%)$ & $d_{\text {mean }}(\mu \mathrm{m})$ & $d_{\max }(\mu \mathrm{m})$ & $\theta_{\text {water }}\left({ }^{\circ}\right)$ & $\theta_{\text {hexadecane }}\left({ }^{\circ}\right)$ & LEP $(\mathbf{b a r})$ \\
\hline PE & 99 & $76 \%$ & 0.30 & 0.43 & 138 & 0 & 3.9 \\
PES & 81 & $58 \%$ & 0.51 & 0.59 & 132 & 92 & 4 \\
PTFE & 77 & $83 \%$ & 0.17 & 0.19 & 120 & 0 & 10.8 \\
\hline
\end{tabular}

\subsection{Prediction of Membrane Wetting with Sodium Dodecyl Sulfate}

\subsubsection{Surface Tension}

The surface tension of the aqueous solution of $35 \mathrm{~g} / \mathrm{L}$ sodium chloride decreases with increasing concentrations of sodium dodecyl sulfate (SDS) (Figure 2). As described in the literature, the surface tension decreases strongly with increasing concentration of SDS up to $50 \mathrm{mg} / \mathrm{L}$, after which an asymptotic level is reached at higher concentrations of sodium dodecyl sulfate [33-35]. This point correlates with the critical micelle concentration (CMC) of the surfactant. For pure water, a the critical micelle concentration of $2560 \mathrm{~g} / \mathrm{L}$ is reported for sodium dodecyl sulfate systems, whereas it is also observed that for salt-containing systems this value is much lower [35]. This means that salinity is an important aspect when studying the wetting behavior of a solution containing surfactants.

The critical surface tension for wetting, defined as the surface tension required to wet the membrane, is also indicated in the figure. Based on this figure, the PE membrane is expected to be wetted by the feed liquid if it contains $50 \mathrm{mg} / \mathrm{L}$ SDS or more. The surface energy of the PTFE and PES membranes is below the asymptotic value of the surface tension of the liquid up to $150 \mathrm{mg} / \mathrm{L}$ and therefore these membranes might be more suitable for treatment of surfactant containing waste streams.

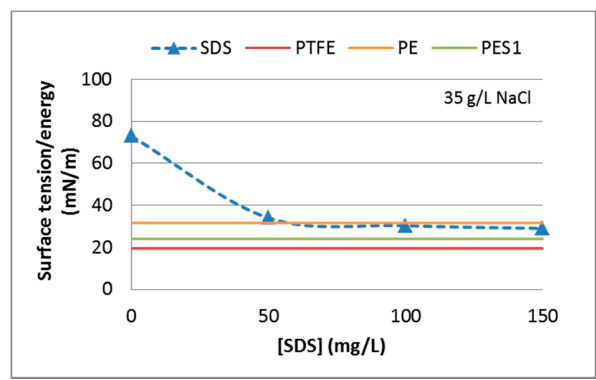

Figure 2. Surface tension as function of sodium dodecyl sulfate (SDS) concentration in an aqueous solution of $35 \mathrm{~g} / \mathrm{L} \mathrm{NaCl}$ and critical surface tension for the membrane surface used in this study.

\subsubsection{Contact Angle}

Figure 3 shows the contact angle of the three different membranes as a function of the sodium dodecyl sulfate concentration. The PTFE and PES membrane show contact angles above $90^{\circ}$ for all SDS concentrations used in this study, whereas the contact angle with PE decreases below $90^{\circ}$ for SDS 
concentrations above $50 \mathrm{mg} / \mathrm{L}$. Based on these results, wetting is only expected for the PE membrane at SDS concentrations higher than $50 \mathrm{mg} / \mathrm{L}$, which confirms the observations in Section 3.2.1.

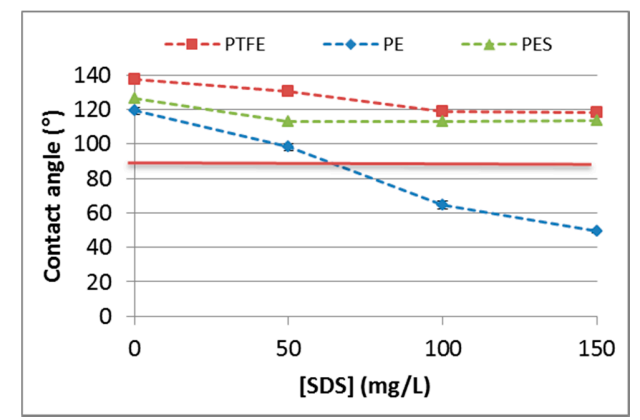

Figure 3. Contact angle measurements at different SDS concentrations, $[\mathrm{NaCl}]=35 \mathrm{~g} / \mathrm{L}$.

\subsubsection{Liquid Entry Pressure}

Figure 4 presents the LEP for the three different membranes for a variety of SDS concentrations and $35 \mathrm{~g} / \mathrm{L} \mathrm{NaCl}$. Up to a concentration of $50 \mathrm{mg} / \mathrm{L}$ SDS no immediate breakthrough of the liquid was observed for a pressure up to 4 bar for all three membranes. The maximum pressure of the experimental setup was 4 bar. Higher liquid entry pressures are therefore not measurable, which is indicated by the hatched bars. The PE and PES membrane shows a strong decline of LEP at higher SDS concentrations. However, in contrast to what was expected based on the surface tension and contact angle measurements, an LEP of 1.8 bar was still achieved at $150 \mathrm{mg} / \mathrm{L}$ SDS for the PE membrane. Neither the PES nor the PTFE membrane showed a severe decrease in contact angle and surface tension. Nevertheless, the lowest LEP of 1.4 bar at $150 \mathrm{mg} / \mathrm{L}$ SDS is observed for the PES membrane, while the PTFE membrane still shows a liquid entry pressure of 3.5 bar. This difference in behavior of the LEP is not expected based on the contact angle measurements, but can be explained due to a difference in pore size (Table 1), which is inversely correlated to liquid entry pressure (Equation (1)). The PES membrane has the highest maximum pore diameter of $0.59 \mu \mathrm{m}$, while the PTFE membrane has a maximum pore diameter of only $0.19 \mu \mathrm{m}$.

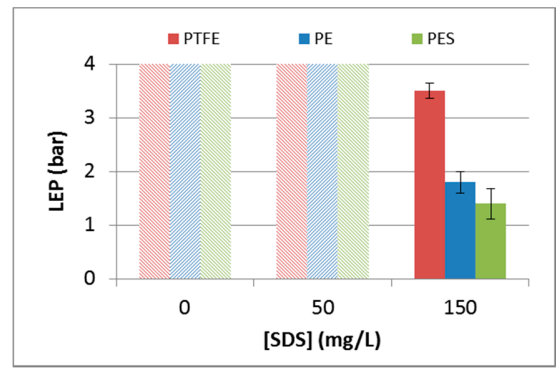

Figure 4. Liquid entry pressure at different SDS concentrations, $[\mathrm{NaCl}]=35 \mathrm{~g} / \mathrm{L}$.

To measure the time dependence of the wetting an additional experiment was carried out. The membrane was placed inside the pressure cell and a constant pressure of 1 bar was applied, using a feed liquid of $150 \mathrm{mg} / \mathrm{L}$ SDS and $35 \mathrm{~g} / \mathrm{L} \mathrm{NaCl}$. The pressure of 1 bar was selected based on the expected pressure drops in a full-scale MD module [36,37]. The PTFE membrane does not show any liquid penetrating the membrane after $30 \mathrm{~min}$, whereas the PE and PES membranes show liquid breakthrough after 11 and $18 \mathrm{~min}$, respectively. This shows that the liquid entry pressure measurements in Figure 4, with a pressure step of 0.1 bar each $30 \mathrm{~s}$ are not representative for long-term membrane operation in membrane distillation. The differences between the MD process and the liquid entry pressure tests might explain this behavior. A few wetted pores are only detected after sufficient time in the liquid entry measurement, while in MD an immediate increase of the permeate conductivity 
is observed. In this respect, membrane distillation is much more sensitive in detection of leakages. The prediction of membrane wetting based on liquid entry pressure using this procedure might therefore be an underestimation and it is recommended that the time dependence must carefully be considered when evaluating the wetting behavior of a membrane.

\subsubsection{Wetting Prediction}

Based on surface tension and the water contact angle, no wetting is expected for the PTFE and PES membrane. The surface tension with a concentration of SDS of $50 \mathrm{mg} / \mathrm{L}$ decreases below the critical surface energy of PE. This is also visualized by the water contact angle, which decreases below $90^{\circ}$ for concentrations above $50 \mathrm{mg} / \mathrm{L}$ SDS. Based on these two techniques, wetting in the MD tests is expected at a concentration of $50 \mathrm{mg} / \mathrm{L}$ SDS. In contrast, the liquid entry pressure for all membranes is above 1.4 bar, while at lab scale a pressure drop of 20 mbar is expected. This indicates that based on liquid entry measurement, no wetting is expected for the lab-scale MD tests. However, at a larger scale, MD pressure drop might increase up to 1 bar. The observation of leakage after applying a hydrostatic pressure difference of 1 bar on the membrane using $150 \mathrm{mg} / \mathrm{L}$ SDS points to possible membrane wetting in full scale modules for the PE and PES membrane.

\subsection{Membrane Distillation with SDS}

\subsubsection{PE}

Figure 5 shows the average flux and salt retention of the PE membrane using different SDS concentrations. Up to $40 \mathrm{mg} / \mathrm{L}$, the flux is unchanged and the salt retention remains sufficiently high (>99.9\%). At $50 \mathrm{mg} / \mathrm{L}$ SDS, the flux increases steadily over time. During the first hour of the experiment at $50 \mathrm{mg} / \mathrm{L}$ SDS, the flux was relatively stable, at $17 \mathrm{~kg} \cdot \mathrm{h}^{-1} \cdot \mathrm{m}^{-2}$, while the retention already decreased from $99.9 \%$ to $98.6 \%$. These observations indicate wetting of a few membrane pores, enabling limited salt transport through the membrane. The fraction of dry membrane pores must be substantially high, because the flux is not affected and the salt retention remains above $98.6 \%$. During the second hour of the experiment, the flux increased rapidly from $17 \mathrm{~kg} \cdot \mathrm{h}^{-1} \cdot \mathrm{m}^{-2}$ up to $40 \mathrm{~kg} \cdot \mathrm{h}^{-1} \cdot \mathrm{m}^{-2}$, while the retention decreased drastically from $>98.6 \%$ to $69.5 \%$, which indicates severe wetting of the PE membrane at these concentrations. The SDS concentration is not further increased above $50 \mathrm{mg} / \mathrm{L}$, because even more severe wetting problems are expected. Based on the contact angle measurements, wetting would occur between 50 and $100 \mathrm{mg} / \mathrm{L}$, while based on the LEP measurement, no wetting is expected up to $1000 \mathrm{mg} / \mathrm{L}$. This shows that the contact angle and surface tension are more reliable measures for prediction of membrane wetting than the LEP. The short-term exposure LEP in Section 3.2.3 did not predict membrane wetting under these experimental condition, and is therefore found to be an unreliable measure for wetting prediction.

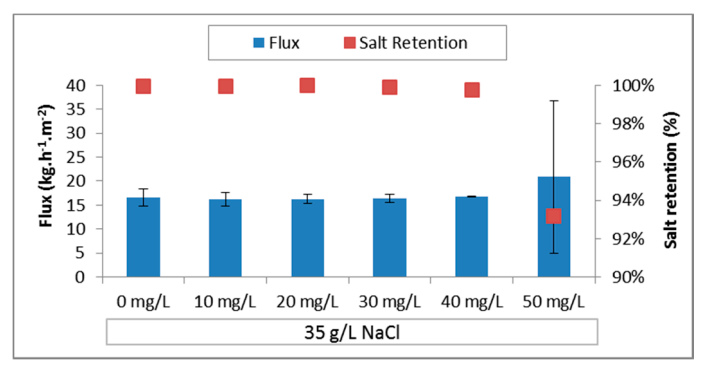

Figure 5. Flux and salt retention for the PE membrane for a feed composition with different SDS concentrations and $35 \mathrm{~g} / \mathrm{L} \mathrm{NaCl}$. 


\subsubsection{PTFE}

The same concentrations of SDS were used with the PTFE membrane. The fluxes and salt retentions for each concentration are given in Figure 6a. The PTFE membrane shows a stable performance over $2 \mathrm{~h}$ of operation up to an SDS concentration of $150 \mathrm{mg} / \mathrm{L}$, as is expected based on the water contact angle and LEP measurements. Figure $6 \mathrm{~b}$ shows the daily average flux and retention for the MD experiment with $150 \mathrm{mg} / \mathrm{L} \mathrm{SDS}$ and $35 \mathrm{~g} / \mathrm{L} \mathrm{NaCl}$. Despite the fact that a stable performance was observed for the short-term experiments over $2 \mathrm{~h}$, longer-term experiments show the intolerance of PTFE membranes for surfactants. Partial pore wetting is gradually provoked by the surfactant and results in salt transport from feed to permeate.

(a)

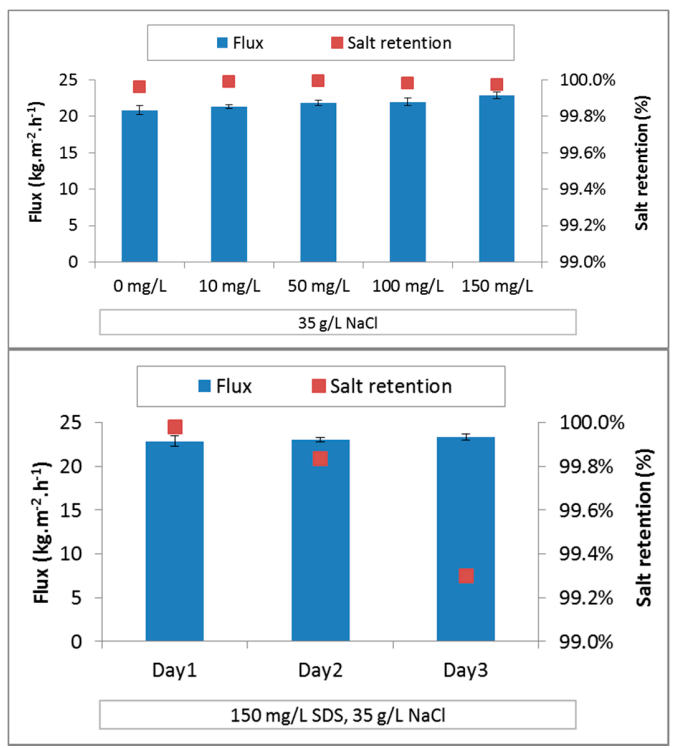

Figure 6. Flux and salt retention for the PTFE membrane; (a) with increasing SDS concentrations; (b) At constant feed composition over three days.

\subsubsection{PES}

In contrast to the PE and PTFE membrane, the flux and retention of the PES membrane did not indicate any wetting at the different SDS concentrations used in this study (Figure 7). In addition, a three-day test at the highest SDS concentration of $150 \mathrm{mg} / \mathrm{L}$ shows salt retention. This behavior is in accordance with the predictions based on the surface tension and the contact angle measurement. The liquid entry pressure of $1.4 \mathrm{bar}$ at $150 \mathrm{mg} / \mathrm{L}$ SDS is sufficient for lab-scale testing, because in the lab setup, the pressure drop did not exceed 0.02 bar for the process conditions used in this study. Nevertheless, it is remarkable that the PES membrane showed a lower LEP compared to the PTFE membrane, while it does show a better salt retention during the MD-tests. As observed during the determination of the critical surface tension, the PES membrane does not wet using hexadecane, proving its oleophobic character. These tests show that this membrane feature can improve the performance of the membrane in terms of wetting resistance in the presence of surface-lowering components. 


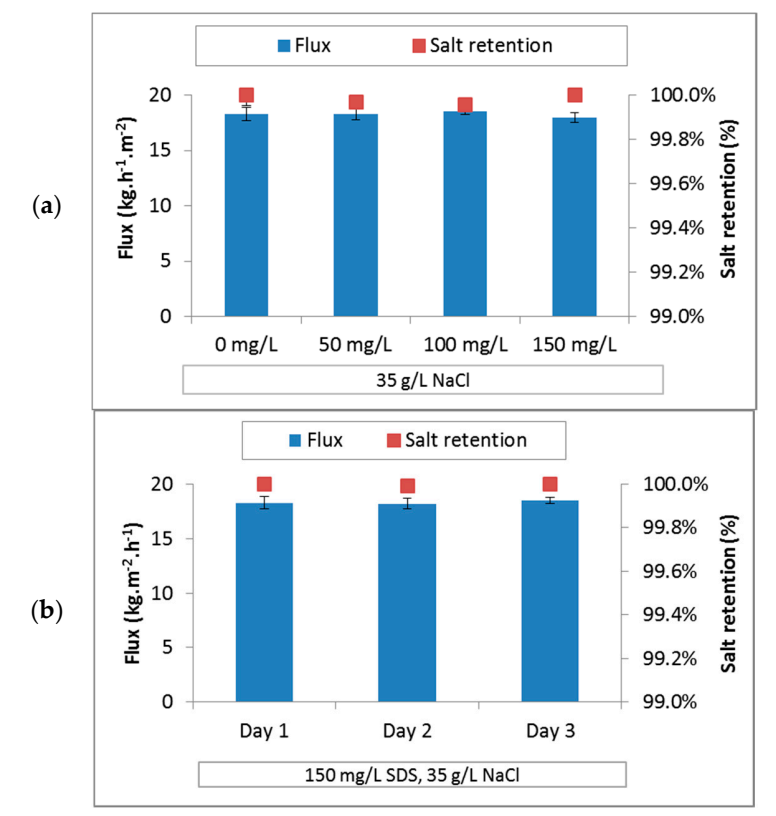

Figure 7. Flux and salt retention for the PES membrane, (a) with increasing SDS concentrations; (b) at constant feed composition over three days.

\subsubsection{Summary}

The best prediction for the immediate wetting in membrane distillation was obtained using the surface tension measurement combined with the contact angle of the fluid with the membrane. Based on this quick and easy measurement, a first estimation of the technical feasibility and a selection of the membrane can be made. However, long-term gradual wetting, as observed with the PTFE membrane, was not predicted by surface tension, contact angle or liquid entry pressure. In addition, when applying the liquid at 1 bar for a longer time $(30 \mathrm{~min})$ no wetting was observed, indicating that the long-term membrane wetting as observed in the PTFE membrane is more difficult to predict using quick analytic experiments.

\subsection{Synthetic Produced Water}

\subsubsection{Prediction of Membrane Wetting}

An emulsion of hexadecane in water was prepared to study the resistance of membrane against wetting in the presence of oily substances. The surface tension of the synthetic produced water was $47 \mathrm{mN} / \mathrm{m}$, which is much higher compared to the lowest surface tension of the solutions with sodium dodecyl sulfate of $\pm 32 \mathrm{mN} / \mathrm{m}$ (Figure 2). It is expected that the sodium dodecyl sulfate forms micelles around the hexadecane, shielding the hexadecane from the air-liquid interface. The oleophobic tail emulsifies the oil, at the same time diminishing its capability of reducing the interfacial air-water surface tension (Figure 8). The contact angle of the synthetic produced water with PTFE and PES was $127^{\circ}$. Membrane wetting was therefore not expected for either membrane. Due to the severe wetting of the PE membrane observed during the SDS experiments, this membrane was not further considered for the treatment of oil emulsions. 

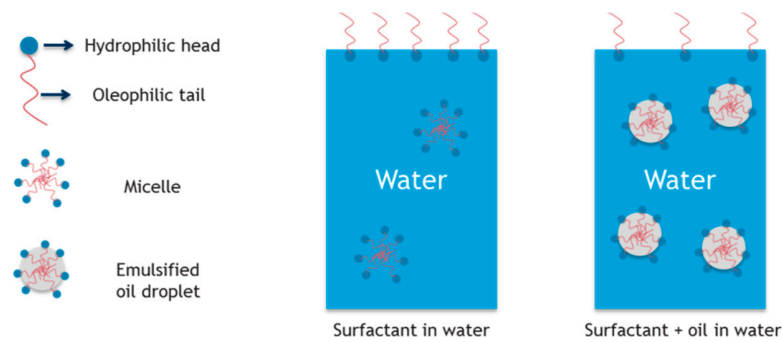

Figure 8. Micelle formation with surfactant in water mixture and emulsification of the oil-in-water mixture.

\subsubsection{Membrane Distillation Testing}

Figure 9 shows the flux of the PTFE and the PES membrane during a one-day test. The flux using the PTFE membrane was stable up to $4 \mathrm{~h}$ of operation. At that moment, water was added to the feed to keep the feed concentration constant. Thereafter, the flux decreases to zero. Figure 10 shows the visual transformation from opaque to transparent of the PTFE membrane, which shows the gradual wetting during the course of the experiment. Remarkably, no increase was observed in permeate conductivity for the PTFE, which remained below $20 \mu \mathrm{S} / \mathrm{cm}$. When refilling the feed vessel with water, the emulsion is locally broken (observed visually) and hexadecane is able to penetrate the membrane. Since the hexadecane and PTFE are both apolar molecules, the membrane takes up the hexadecane, which remains in the membrane and blocks the flux. Sodium chloride is not soluble in hexadecane, explaining the unexpected combination of flux decrease due to membrane wetting, without loss of salt retention. In contrast to PTFE, the flux of the PES membrane only steadily decreases, with only 9\%. No visual observation of wetting was observed for this membrane, however the steady decrease might indicate that some of the pores are also blocked by the hexadecane, reducing the flux, causing the slight decrease in flux.

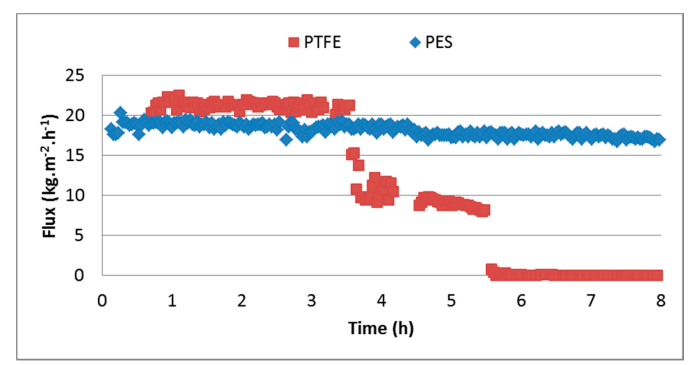

Figure 9. Flux as function of time for PTFE and PES with the oil/SDS mixture as feed solution.

(a)

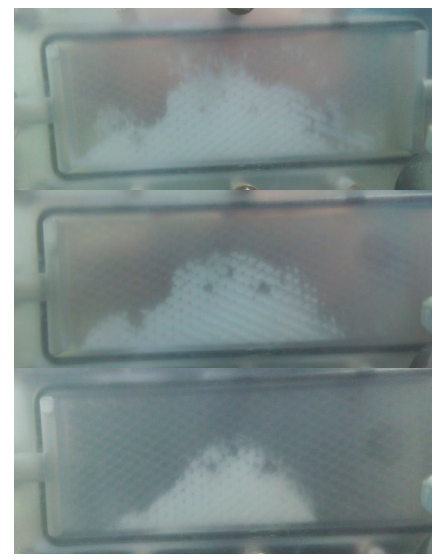

Figure 10. Pictures of the PTFE membrane during the experiment with oil/SDS mixture after (a) $4 \mathrm{~h}$; (b) $5 \mathrm{~h}$; (c) $6 \mathrm{~h}$ of MD operation. 


\section{Conclusions}

In this manuscript it was shown that immediate wetting in membrane distillation can be predicted by surface tension and water contact angle measurements. The surface tension measurement shows that wetting behavior might not only depend on sodium dodecyl concentration, but also on the $\mathrm{NaCl}$ concentration, which strongly affects the critical micelle concentration. The PE membrane is less hydrophobic compared to PTFE and is therefore more susceptible towards membrane wetting due to the presence of surfactants. This membrane shows immediate wetting, a severe salt increase in the permeate, and a flux increase induced by the hydrostatic pressure difference. For PTFE the short-term test did not show changes in salt retention for SDS concentrations far above the critical micelle concentration (SDS: $150 \mathrm{mg} / \mathrm{L}, \mathrm{NaCl}: 35 \mathrm{~g} / \mathrm{L}$ ). However, three-day MD testing shows that despite the sufficiently high contact angle with the PTFE-membrane, a decrease of the salt retention is observed, while still maintaining stable fluxes. This shows that the wetting is much less severe compared to the PE membrane, but that at longer operational times membrane wetting might also become an important issue. The PES membrane is oleophobic and showed unaffected flux or salt retention over three days of testing. Additionally, membrane distillation experiments with synthetic produced water showed the better stability in performance of an oleophobic membrane compared to a hydrophobic PTFE membrane.

Acknowledgments: Lies Eykens thankfully acknowledges a PhD scholarship provided by the Flemish Institute for Technological Research, VITO NV.

Author Contributions: Lies Eykens performed and analyzed the experiments and wrote the paper. All other authors contributed significantly through their guidance and support during the experiments and the writing process.

Conflicts of Interest: The authors declare no conflict of interest.

\section{References}

1. Lin, S.; Yip, N.Y.; Elimelech, M. Direct contact membrane distillation with heat recovery: Thermodynamic insights from module scale modeling. J. Membr. Sci. 2014, 453, 498-515. [CrossRef]

2. Kesieme, U.K.; Milne, N.; Aral, H.; Cheng, C.Y.; Duke, M. Economic analysis of desalination technologies in the context of carbon pricing, and opportunities for membrane distillation. Desalination 2013, 323, 66-74. [CrossRef]

3. Sha, D.L.; Chavez, L.H.A.; Ben-sasson, M.; Castrillo, S.R. Desalination and Reuse of High-Salinity Shale Gas Produced Water: Drivers, Technologies, and Future Directions. Environ. Sci. Technol. 2013, 47, 9569-9583.

4. Alkhudhiri, A.; Darwish, N.; Hilal, N. Treatment of high salinity solutions: Application of air gap membrane distillation. Desalination 2012, 287, 55-60. [CrossRef]

5. Duong, H.C.; Chivas, A.R.; Nelemans, B.; Duke, M.; Gray, S.; Cath, T.Y.; Nghiem, L.D. Treatment of RO brine from CSG produced water by spiral-wound air gap membrane distillation-A pilot study. Desalination 2015, 366, 121-129. [CrossRef]

6. Ge, J.; Peng, Y.; Li, Z.; Chen, P.; Wang, S. Membrane fouling and wetting in a DCMD process for RO brine concentration. Desalination 2014, 344, 97-107. [CrossRef]

7. Martinetti, C.R.; Childress, A.E.; Cath, T.Y. High recovery of concentrated RO brines using forward osmosis and membrane distillation. J. Membr. Sci. 2009, 331, 31-39. [CrossRef]

8. Criscuoli, A.; Zhong, J.; Figoli, A.; Carnevale, M.C.; Huang, R.; Drioli, E. Treatment of dye solutions by vacuum membrane distillation. Water Res. 2008, 42, 5031-5037. [CrossRef] [PubMed]

9. El-Abbassi, A.; Hafidi, A.; Khayet, M.; García-Payo, M.C. Integrated direct contact membrane distillation for olive mill wastewater treatment. Desalination 2013, 323, 31-38. [CrossRef]

10. Prince, J.A.; Singh, G.; Rana, D.; Matsuura, T.; Anbharasi, V.; Shanmugasundaram, T.S. Preparation and characterization of highly hydrophobic poly(vinylidene fluoride)-Clay nanocomposite nanofiber membranes (PVDF-clay NNMs) for desalination using direct contact membrane distillation. J. Membr. Sci. 2012, 397-398, 80-86. [CrossRef]

11. Thiel, G.P.; Tow, E.W.; Banchik, L.D.; Chung, H.W.; Lienhard, J.H. Energy consumption in desalinating produced water from shale oil and gas extraction. Desalination 2015, 366, 94-112. [CrossRef] 
12. Warsinger, D.M.; Swaminathan, J.; Guillen-Burrieza, E.; Arafat, H.A.; Lienhard, J.H. Scaling and fouling in membrane distillation for desalination applications: A review. Desalination 2015, 356, 294-313. [CrossRef]

13. Hausmann, A.; Sanciolo, P.; Vasiljevic, T.; Weeks, M.; Schroën, K.; Gray, S.; Duke, M. Fouling mechanisms of dairy streams during membrane distillation. J. Membr. Sci. 2013, 441, 102-111. [CrossRef]

14. Tijing, L.D.; Woo, Y.C.; Choi, J.S.; Lee, S.; Kim, S.H.; Shon, H.K. Fouling and its control in membrane distillation-A review. J. Membr. Sci. 2015, 475, 215-244. [CrossRef]

15. Hausmann, A.; Sanciolo, P.; Vasiljevic, T.; Weeks, M.; Schroën, K.; Gray, S.; Duke, M. Fouling of dairy components on hydrophobic polytetrafluoroethylene (PTFE) membranes for membrane distillation. J. Membr. Sci. 2013, 442, 149-159. [CrossRef]

16. Nguyen, Q.M.; Lee, S. Fouling analysis and control in a DCMD process for SWRO brine. Desalination 2015, 367, 21-27. [CrossRef]

17. Guillen-Burrieza, E.; Ruiz-Aguirre, A.; Zaragoza, G.; Arafat, H.A. Membrane fouling and cleaning in long term plant-scale membrane distillation operations. J. Membr. Sci. 2014, 468, 360-372. [CrossRef]

18. Curcio, E.; Ji, X.; Di Profio, G.; Sulaiman, A.O.; Fontananova, E.; Drioli, E. Membrane distillation operated at high seawater concentration factors: Role of the membrane on $\mathrm{CaCO}_{3}$ scaling in presence of humic acid. J. Membr. Sci. 2010, 346, 263-269. [CrossRef]

19. Nghiem, L.D.; Cath, T. A scaling mitigation approach during direct contact membrane distillation. Sep. Purif. Technol. 2011, 80, 315-322. [CrossRef]

20. Garcia-Payo, M.M.C.; Izquierdo-Gil, M.A.M.; Fernandez-Pineda, C. Wetting Study of Hydrophobic Membranes via Liquid Entry Pressure Measurements with Aqueous Alcohol Solutions. J. Colloid Interface Sci. 2000, 230, 420-431. [CrossRef] [PubMed]

21. Gryta, M.; Barancewicz, M. Influence of morphology of PVDF capillary membranes on the performance of direct contact membrane distillation. J. Membr. Sci. 2010, 358, 158-167. [CrossRef]

22. Gryta, M. Concentration of $\mathrm{NaCl}$ solution by membrane distillation integrated with crystallization. Sep. Sci. Technol. 2002, 37, 3535-3558. [CrossRef]

23. Bilad, M.R.; Guillen-Burrieza, E.; Mavukkandy, M.O.; Al Marzooqi, F.A.; Arafat, H.A. Shrinkage, defect and membrane distillation performance of composite PVDF membranes. Desalination 2015, 376, 62-72. [CrossRef]

24. Lalia, B.S.; Guillen-Burrieza, E.; Arafat, H.A.; Hashaikeh, R. Fabrication and characterization of polyvinylidenefluoride-co-hexafluoropropylene (PVDF-HFP) electrospun membranes for direct contact membrane distillation. J. Membr. Sci. 2013, 428, 104-115. [CrossRef]

25. Franken, A.C.M.; Nolten, J.A.M.; Mulder, M.H.V.; Bargeman, D.; Smolders, C.A. Wetting criteria for the applicability of membrane distillation. J. Membr. Sci. 1987, 33, 315-328. [CrossRef]

26. Lin, S.; Nejati, S.; Boo, C.; Hu, Y.; Osuji, C.O.; Elimelech, M. Omniphobic Membrane for Robust Membrane Distillation. Environ. Sci. Technol. Lett. 2014, 1, 443-447. [CrossRef]

27. Wang, Z.; Hou, D.; Lin, S. Composite Membrane with Underwater-Oleophobic Surface for Anti-Oil-Fouling Membrane Distillation. Environ. Sci. Technol. 2016, 50, 3866-3874. [CrossRef] [PubMed]

28. Zuo, G.; Wang, R. Novel membrane surface modification to enhance anti-oil fouling property for membrane distillation application. J. Membr. Sci. 2013, 447, 26-35. [CrossRef]

29. Mustafa, G.; Wyns, K.; Buekenhoudt, A.; Meynen, V. Antifouling grafting of ceramic membranes validated in a variety of challenging wastewaters. Water Res. 2016, 104, 242-253. [CrossRef] [PubMed]

30. Khayet, M.; Matsuura, T. Preparation and Characterization of Polyvinylidene Fluoride Membranes for Membrane Distillation. Ind. Eng. Chem. Res. 2001, 40, 5710-5718. [CrossRef]

31. Eykens, L.; De Sitter, K.; Dotremont, C.; Pinoy, L.; Van der Bruggen, B. Characterization and performance evaluation of commercially available hydrophobic membranes for direct contact membrane distillation. Desalination 2016, 392, 63-73. [CrossRef]

32. Eykens, L.; Hitsov, I.; De Sitter, K.; Dotremont, C.; Pinoy, L.; Nopens, I.; Van der Bruggen, B. Influence of membrane thickness and process conditions on direct contact membrane distillation at different salinities. J. Membr. Sci. 2016, 498, 353-364. [CrossRef]

33. Hernáinz-Bermúdez de Castro, F.; Gálvez-Borrego, A.; Calero-de Hoces, M. Surface Tension of Aqueous Solutions of Sodium Dodecyl Sulfate from $20^{\circ} \mathrm{C}$ to $50{ }^{\circ} \mathrm{C}$ and pH between 4 and 12. J. Chem. Eng. Data 1998, 43, 717-718. [CrossRef] 
34. Kloubek, J. Measurement of the dynamic surface tension by the maximum bubble pressure method. IV. Surface tension of aqueous solutions of sodium dodecyl sulfate. J. Colloid Interface Sci. 1972, 41, 17-22. [CrossRef]

35. Owens, D.K.D. The dynamic surface tension of sodium dodecyl sulfate solutions. J. Colloid Interface Sci. 1969, 29, 496-501. [CrossRef]

36. Hitsov, I.; Eykens, L.; De Schepper, W.; De Sitter, K.; Dotremont, C.; Nopens, I. Full-scale Direct Contact Membrane Distillation (DCMD) model including membrane compaction effects. J. Membr. Sci. 2017, 524, 245-256. [CrossRef]

37. Winter, D.; Koschikowski, J.; Wieghaus, M. Desalination using membrane distillation: Experimental studies on full scale spiral wound modules. J. Membr. Sci. 2011, 375, 104-112. [CrossRef]

(C) 2017 by the authors; licensee MDPI, Basel, Switzerland. This article is an open access article distributed under the terms and conditions of the Creative Commons Attribution (CC BY) license (http:/ / creativecommons.org/licenses/by/4.0/). 